SHS Web of Conferences 10, 00008 (2014)

DOI: $10.1051 /$ shsconf $/ 20141000008$

C Owned by the authors, published by EDP Sciences, 2014

\title{
Programme evaluation - Case work with families and children in Riga
}

\author{
M. Filipova and M. Moors \\ Rīga Stradinsš University, Latvia
}

\begin{abstract}
Since 2003, the professional social work has been acknowledged as a professional occupation. In compliance with the Social Service and Social Assistance Law (further - Law), local municipalities are responsible for carrying out individual work with families and children, where there are negative preconditions for the development of a child.

The city of Riga is the capital of Latvia and the largest municipality with the broadest spectrum of experience in providing social assistance and social services. Riga can boast with the two-levelled organisation of social work: direct social work with a client is carried out at Riga Social Office; however, social assistance and its programme administration is the responsibility of Welfare Department of Riga.

Data show that especially during the period of economic crisis and after-crisis period the number of clients of social workers - families - has markedly increased. If back in 2008, up to 3063 families needed social assistance and social services; in 2011, the number of families in need of such assistance had already reached 3216 . This indicates the steady growth of social work in Riga.

In 2011, social services and social assistance to 3216 families was provided with the help of 66 social workers. The total number of people served reached 11,947 persons; the number included 7.565 adults and 4.868 children. ${ }^{1}$ These families frequently suffer from depression, alcoholism, drug addiction; they are exposed to potential risks of poverty and family violence, as well as may develop criminal cases. Those families where any of the above mentioned risks are present suffer from dysfunctional familial relationships. One of the services provided to such families is individual case work. The service helps families with children to define, solve or lessen social problems by developing the resources of the involved individuals and by employing various systems of assistance. The number of social service workers in Riga Social Office is rather unchangeable; however, clients with problems of multiple and complicated nature increase.

Evaluation is a crucial part of every professional activity. It is not a rare case that in Latvia the evaluation of the provided service means formally defining what has been done, for example, the number of consultations provided during face to face meetings and over the phone, the number of visitations, the number of the produced informative letters, the number of the services provided or the number of cases per social worker a year.

The aim of the study is to evaluate the quality of the case work system in providing social assistance. The research involved the unity of all the activities undertaken by a social worker when focusing on case work. Quality assessment criteria were defined for the sake of carrying out the research.
\end{abstract}

\footnotetext{
${ }^{1}$ Riga Welfare Department YEARBOOK “Sociālā sistēma un veselības aprūpe Rīgā 2011. gadā” (Social work system and health care in Riga in 2011), Riga, 2012. - pp. 35. (http://www.ld.riga.lv/labklajibas-departamenta-gadagramatas.html - accessed on 14.10.2013.)

This is an Open Access article distributed under the terms of the Creative Commons Attribution License 4.0, which permits unrestricted use, distribution, and reproduction in any medium, provided the original work is properly cited.
} 


\section{SHS Web of Conferences}

\section{Materials and methods}

In order to reach the aim of the study, i.e., evaluate the quality of social service - case work with families and children - empirical study was carried out between November and December of 2012.

The research was performed as an evaluation research, also known as programme evaluation, which includes seeking practical knowledge in order to estimate the interference made by a social worker on the social well-being of their client. Evaluation involves systematic assessment of the programme or the results of the actions undertaken by a social worker in comparison with intentionally or unintentionally defined standards/aims. ${ }^{2}$

The method of the research was case analysis. The authors of the study analysed cases of 100 families which were closed in $2011^{3}$. General group consists of 1342 cases obtained from Riga Social Office, out of which every $10^{\text {th }}$ case was chosen based on the matter of luck. The sampling of the cases was done with the help of the informative system used for administering social benefits in the local municipality by selecting cases due to the reasons of their closure - "improvement of the situation". To have equal proportion of every part of the City of Riga, the general group was geographically divided in three regional units, which complies with the division of Riga Social Office: Ziemeļu Unit, Pārdaugava Unit, Latgale Unit.

\section{Materials}

For the analysis of the cases a specifically design questionnaire was used. As the basis of the questionnaire were used:

1. the defined requirements of the Department ${ }^{4}$ about the client case compilation and the information it is supposed to contain;

2. the division of six intervention phases ${ }^{5}$ quoted from Joseph Heffernan, Guy Shettlesworth and Rosalie Ambrosino - 1. Social case learning phase, 2. Initial information evaluation phase, 3. Target activity definition phase, 4. Agreement phase, 5. Choice of Tactics and Techniques phase, 6. Overall social case evaluation phase.

3. Clarification design by the authors - assessment criteria for every point of measurement.

For quality assessment in social work, the authors of the Paper evaluated the process of the case and the obtained results. When doing the assessment, the focus was on the activities that had to be undertaken at a certain phase of intervention, the compliance of the case with the requirements of the Department, which included both the formal criteria, i.e. the presence of specific documentation, and the evaluation of the direct action undertaken when dealing with the case. However, when evaluating the obtained result of social work, the changes that have taken place in the client's life in comparison with the initially

\footnotetext{
${ }^{2}$ Engel R., Schut R., The Practice of Research in Social Work - Thousand Oaks, London, New Delhi: Sage Publications. 2005. pp. 13.

3 Clients case is considered as a closed one if the set targets of case work have been reached and/or when no further interference from a social worker's side is needed: if a social worker has started a case work, but the client is resistant to any further cooperation (if the client is a family with children, it is applicable to families with weak dysfunctional characteristics); if social work has completely been undertaken by a different institution; if the client has changed their place of residence. In such cases the client's case is closed and the closure must be agreed with the manager of Riga Social Office senior social worker of Territory Unit, by providing reasons for the case closure and making necessary changes in SOPA database. The case is to be kept at Riga Social Office archive.

${ }^{4}$ Riga Welfare Department 27.04.2011. Regulations No.DL-11-16-nts "About the Required Documentation of Client Cases of Riga Welfare Department", which define the volume of the required documentation and activities that have to be undertaken with case work.

5 Ambrosino, R., Heffernan, J., Shuttlesworth, G., Social Work and Social Welfare: An Introduction/3rd ed. - St.Paul: West Publishing Company.1997. - pp. 106-107.
} 


\author{
Int. Conf. SOCIETY. HEALTH. WELFARE.
}

defined problems and defined targets was taken into account. According to the authors of this respective study, social work with a case quality is connected with the achievement of 13 criteria. In other words, if the criteria have been matched, the work done can be treated as a quality one.

Every criterion was assessed according to the level of completion: fully completed, partly completed or not completed, by giving every criterion its numerical value. Three points were given in cases of full accomplishment according to the requirements of the criterion. Two points were given for partly accomplished requirements. A point was given in cases when the requirements were not met due to the circumstances that had to be taken into account. However, zero points were given for completely not meeting the criteria or completing the service by not complying with any requirements

Below the descriptions of assessment of every criterion is given.

\title{
Criterion 1 - Accordance with the requirements of the Department
}

Regulations of Riga Welfare Department define the volume of the required documentation and activities that have to be undertaken when carrying out case work. The aim of the Regulations is to specifically define what documentation is to be completed in doing case work, thus targeting towards effective accomplishment of social worker's activities undertaken in every case: data collection, systemisation, and monitoring of the process. The required documentation includes: client's case (title page of the case, overview of the activities undertaken, contacts page, evaluation of the social situation), social and case work plan, individual's social rehabilitation plan, agreement with the client, assessment of social work in doing case work. Within the respective study, the authors of the Paper analysed whether the defined requirements are met and whether social workers use the required documentation, also the quality of its completion. If the requirements were completed fully, and every case contained all necessary document pages, which were completed according to the Regulations, the criterion was awarded three points. However, in cases of partly completed requirements, or when there were not all the document pages, or upon partial completion or document pages, the criterion was awarded two points. Zero points were given when the requirements were not met and the case did not comply with the Regulations.

\section{Criterion 2 - Basic information about the client and other family members; social situation of the family}

In this aspect, we focussed on analysis whether all the names of people addressed by a social worker were noted down; whether the information has been obtained and recorded about all the family members in doing case work, as it is important for a social worker to be aware of the client's needs and the support system that might be efficient to help the respective client. The obtained information may lead to a much clearer understanding of the case, the desired outcome of it may be anticipated, in addition, it also helps with defining the necessary services for the particular case, etc. If the information about the clients, their family members and social situation of the family has been obtained and recorded, the criterion is considered to have been fully completed, thus three points are awarded. If the information is partially gathered, and there was lack of information about family members, the criterion is partially completed and is awarded two points. However, zero points were given when there was no information recorded about neither the clients nor their family members.

\section{Criterion 3 - Characteristics of the case/ defining of the problem}

The quality of social work in case work can be measured when the problem of the case has been clearly defined, i.e., the problem affecting client's well-being and effective social functioning has to be detected. The criterion is awarded three points when the problem is clearly defined and allows for formation of 
measureable targets to reach. Precise formulation of the problem leads to a purposeful planning on the intervention and required steps to be undertaken in order to obtain the expected outcome of such activity. If the formulation of the problem has been too vague and/or inappropriate for the social situation of the client, the criterion is considered as partially completed and is awarded two points. It must be admitted that without clear definition of the target problem, social worker will be unable to help the client and reach any change in the course of action. However, the criterion is considered not completed and awarded zero points if there is no definition of the target problem in the file.

\section{Criterion 4 - Evaluation of the initial situation}

The definition of the problem from client's perspective was included as part of the information of the evaluation of the social situation of the client; i.e. a social worker was to record the problem as the client had spoken about it. Another part of such evaluation was the assessment of social functioning of the client, which included aspects like housing, education, employment, health, relationships, income level and management of financial resources. The criterion is completed and awarded three points if the assessment of the respective social situation has been done in it fullest. The obtained information allows for clear understanding of the client's situation, helps to detect those areas where the client is struggling with social functioning. Upon partial assessment of social situation, the criterion is considered as partially completed and is awarded two points. The criterion is incomplete and awarded zero points if there has not been any assessment of the social situation or it has never been recorded in the client's file.

\section{Criterion 5 - Assessment of risks}

In cases when the client is a dysfunctional family with negative factors of the development of a child, it is crucial to evaluate the potential risk factors, i.e., unified and holistic criteria are used for the assessment of the factors that may affect the physical and psychological development and well-being of a child ${ }^{6}$. If there has been in-depth risk assessment, high risks and possible solutions detected, the professionals and/or appropriate institutions (custody court, police, etc.) informed, which all has been backed up with appropriate records in the client's file, the criterion can be considered successfully completed and is awarded three points. However, in cases when risk assessment has been done insufficiently, i.e., no conclusions of child and/or parent risk assessment have been provided, and no necessary steps defined in the Rehabilitation plan, the criterion is partially completed and is awarded two points. In cases when there has been no assessment of risk factors in families with negative conditions for a child's development, the criterion is not completed and is awarded zero points. The authors of this respective study indicate of the possible danger when there has been no timely assessment of risk factors in such families. This may lead to irreversible influences on the development of a child's mental and physical well-being, in extreme cases may even lead to exposing a child to danger of their life.

\section{Criterion 6 - Signed agreement/contract between the client and a social worker}

The authors of the study analysed the content, its applicability for the desired outcome and the terms of completion of the respective tasks of the signed agreements between clients and social workers. If the tasks are defined clearly and are of attainable character, lead towards the solution of the problem, the terms of accomplishment of the tasks defined percisely, can be completed in a timely manner, are

\footnotetext{
6 Risk assessment in the families with negative factors affecting the development of a child is defined by the Regulations of the Cabinet of Ministers No291 (January 3, 2003), "Regulations for social service providers".
} 


\author{
Int. Conf. SOCIETY. HEALTH. WELFARE.
}

reasonable, and upon the completion of the agreement there is a client's signature and date or mark why the tasks were unable to be completed, the criterion is considered as having been successfully accomplished and is awarded three points. However, in cases when the tasks have been defined clearly and aim towards the solution of the respective problem, but the terms of accomplishment are rather vague, not set in definite time, for example, they are "to be completed while the agreement has its force", the criterion is partially completed and is awarded two points. If the tasks are defined too generally, for instance, "to take part in rehabilitation processes in order to maintain work and socialisation skills or their renewal, or the acquisition of those", no terms of accomplishment of the tasks have been defined and there is absence of the client's signature, the criterion is not completed and is awarded zero points. The authors of this research believe that the tasks must be selected with special care by specifically defining what there is to be done, and they should be adjusted to the needs of every client. The accomplishment or lack of such accomplishment allows a social worker to confront the client with their own understanding of the respective problem that is in need of solution.

\title{
Criterion 7 - Designed plan of intervention or interposition
}

Upon analysis of the content of the plan, the authors of the study defined the following characteristics of evaluation:

- Clearly defined aims and tasks, and obtained results for each individual problem.

- Explicit description of the steps for completing the aim, doable activities, clearly defined deadlines.

- The plan covers the basic information on:

○ identifiable and solvable social problems;

$\circ$ aims of interference;

- tasks to be accomplished for a social worker and the client:

- timetable;

- envisaged obstacles;

- strengths (for example, resources obtained for solving social problems of the client);

$\circ$ evaluation of the intervention.

If every above mentioned feature has been included in the intervention plan design, the criterion has been successfully completed and is awarded three points. However, if the intervention plan is identical to the former plans, but the aims and required tasks are vaguely defined, are unclear, and there is lack of timetable and evaluation of intervention, the criterion is partially completed and is awarded two points. If there is absence of intervention plan or it is missing from the client's file, the requirements of the criterion are not met and it is awarded zero points.

\section{Criterion 8 - Assessment of inter-professional and/or inter-institutional cooperation}

In managing social work, social workers cooperate with various institutions of different fields and a wide range of specialists. The Social Service and Social Assistance Law recognises inter-professional and inter-institutional cooperation as one on the basic principles of providing efficient social services. If doing case work other professionals have contributed to finding solutions to the problem by following prescribed tasks, but the tasks have not been completed, it may affect successful accomplishment of the set targets and improvement of the client's situation. If the case has been the focus of interinstitutional meeting, the involved parties are aware of their tasks to be completed, those have been realised and documented in the client's file, thus proving the reaching of the aims, or if the note has 
been made on the objective obstacles that have affected the accomplishment of such aims, the criterion is considered completed and is awarded three points. However, if the case has been the focus of interinstitutional meeting, with specifically designed tasks for the involved parties, but the client's file lacks the description of the activities undertaken by those parties, the criterion is considered as partially completed and is awarded two points. If the case has been the focus of inter-institutional meeting, specific tasks have been defined for the involved parties, which have never been realised; the criterion is not completed and is awarded zero points.

\section{Criterion 9 - Obtained resources}

In order to reach the development and stability of social functioning of a family, social assistance instruments are implemented; thus, the authors of the Paper analysed the assistance services provided and whether those were in accordance with the assessment of the client's needs. The criterion was considered complete and awarded three points if the evaluation indicated on targeted work with families, the obtained resources have been chosen appropriate to the solvable problem and the needs of the client. If social services have been partly used, no appropriate assistance resources have been offered or it is difficult to reason the use of a particular service in terms with the needs of reaching the aim or solving the particular problem, the criterion is partially completed and is awarded two points. Nevertheless, if upon the evaluation of the family's needs there was detected the necessity for particular services or specialists, but those have not been attracted to the solution of the target problem, the criterion is not completed and is awarded zero points.

\section{Criterion 10 - Reflected/evaluated cooperation dynamics between the client and social worker}

Social case work requires periodic evaluation so that the changes of the social situation of the client can be detected. The aim of the evaluation is to assess the obtained results and decide upon the further course of action, which all has to be done in cooperation with the respective client. The dynamics of client cooperation and changes in the client's situation are likely to be under the scope of evaluation. In cases when the evaluation of cooperation dynamics between the client and social worker is assessed regularly, the same is applied to the analysis of factors fostering or hindering the cooperation, when systematic evaluation of the plan of intervention takes place, and new targets, tasks and activities are defined in case of necessity, the criterion is completed entirely and thus awarded with three points. However, if no cooperation dynamics between the client and social worker are evaluated, but there has been the evaluation from the side of social worker without defining exact methods applied, there is no assessment of the factors facilitating or hindering the cooperation, thus no new targets, tasks or activities are defined; this all leads to the criterion being completed only partially and thus it is awarded two points. If the evaluation equals the previous ones or there is no such evaluation performed, no clear process of cooperation is present, and there has not been any assessment of the dynamics of such cooperation, the criterion is not completed and is awarded zero points.

\section{Criterion 11 - Evaluation of results of case work by a social worker when the case work is considered completed}

If evaluation is performed, recommendations on further observation of the client given and activities that would maintain the positive situation for the client overlooked, the criterion is completed and awarded three points. If the evaluation has been performed, but no recommendations on further observation of the client or suggested course of action defined, especially in cases when it is needed, the criterion is 
Int. Conf. SOCIETY. HEALTH. WELFARE.

partially completed and is awarded two points. When there is no evaluation of the results of social work performed, the requirements of the criterion have not been met, it is awarded zero points.

\section{Criterion 12 - Compatibility of the aim with the expected results}

The authors of the study analysed the compatibility level between the final results and the targets set in the intervention plan. If the aim has been fully reached and the result is in compliance with the desired outcome of actions carried out when helping the client, the criterion is completed and awarded three points. However, upon partial reaching of the aim, and when the outcome only partially complies with the targets set in the intervention plan, the criterion is considered as partially completed and is awarded two points. The criterion is not completed and awarded zero points if the aim has never been reached and the result does not comply with the expected outcome, and also in cases when criterion 11 has not been completed.

\section{Criterion 13 - Closure of the case}

If the closure of the case has been agreed with the manager of the Territory Unit or senior social worker, under the supervision of whom social worker performs, by defining the cause of closure and the record has been made in the informative system used for administering social benefits and social services in the local municipality (client database), in cases when there has been relocation of the client, the information, including characterisation of the social situation of the client, resources available and actions undertaken, has been passed on to a different social worker who performs in the area of the real residence of the respective person, the criterion is considered fully completed. However, if the closure of the case has been agreed with the manager of the Territory Unit or senior social worker, the cause of the closure has been defined and the changes recorded in the informative system used for administering social benefits in the local municipality, when the client has changed their place of residence, the information about the client is available in limited amount, is insufficient or there is no information at all, the criterion is partially completed and is awarded two points. If the closure of the case has not been agreed with the manager of the Territory Unit or senior social worker, no cause for the closure has been provided and no record has been made in the informative system used for administering social benefits in the local municipality, the criterion is not completed and is awarded zero points.

Thus, if all 13 criteria were accomplished, the maximum points scored would be $36^{7}-39$, which indicates the high quality performance of a social worker, as all the requirements described in the scientific literature on case work, and those stated in the Regulations of Riga Welfare Department have been observed. Partial completion of the criteria would allow one to score between $23^{6}-26$ points. 36 points is the lowest one may get if the criteria have been successfully met; however, the lowest level for partial completion of the criteria is 23 points. Written agreement with volunteering clients is not a necessity in a few cases. In the cases where the score varies between 27 to 35 points, one or several criteria have not been fully completed.

The approbation process of the evaluation questionnaire was carried out before the performance of this study. The authors of the Paper asked four independent experts - senior social workers of Riga Social Office, who are responsible for the supervision of social workers in detecting social problems of their clients and management of case work - perform a few clients' case analysis by using the evaluation questionnaire, and their assessment and commentaries of the tool were required as well. During the process of approbation the scale of efficiency was adjusted so it would be more exact - definitions were

\footnotetext{
${ }^{7}$ Excluding criteria 5, 6 and 8 of the evaluation questionnaire, as the performance of these may not be required in all cases, for example, upon the management of case work there is no need to assess team design of inter-professional team, the same applies for the evaluation of social risks.
} 


\section{SHS Web of Conferences}

elaborated and made more specific, and words like "in-depth", "precise", "all" were excluded from tem to avoid ambiguity that may arise when performing the evaluation process.

\section{Results}

The best quality measurement tool is the effect social assistance can give to successful social functioning of a client. Nevertheless, equally important is the quality performance of a social worker. This aspect has gained a central role in this study. For quality assessment, within the process of research the authors of the Paper gave every criterion its numerical value, which leads to the conclusion that quality is obtained upon scoring 36-39 points. The analysis of client cases revealed the following:

1. Out of 100 client cases, the maximum score was reached in 34, which indicates that performing these 34 cases social workers had observed every single requirement defined in every phase of intervention and those stated in the Regulations of Riga Welfare Department. In other words, this has been a $100 \%$ quality performance. When analysing the cases with the score of 36-39 points, it was concluded that a few insignificant lapses were possible, for example, there was a partial completion of criterion 8 or it was not completed at all. It allows for the conclusion that social workers have performed up to the highest standards in these cases, and their actions have contributed to the change and improvement of social functioning abilities of the clients.

2. 46 cases exposit between 8 and 11 fully completed criteria, which has to be treated as a decent result, especially being aware that completion of a few criteria may not be necesary ${ }^{5}$. The number of unaccomplished or partly completed criteria varies between 1 and 2 , and the total sum of points is 29-35. The main, domineering partly completed criteria in these cases were criteria No. 2, 10, 11 and 12. However, criteria No. 4, 6 and 7 were not competed at all. When analysing these cases, it was detected that in 31 cases there was no need to complete criterion No. 8, among which criterion No. 5 was not needed to be completed in 7 cases; as the result the total score of these cases was lowered by one or two criteria. Thus, when counting the score in these cases, the maximum points were not obtained with the help of 13 criteria, thus the cases can be considered to be qualitative ones.

3. In 14 cases where the total score is between 23 and 27 points, the number of partially completed criteria is not lower than 9, which is important when planning case work and evaluating the obtained results. Moreover, almost none of the criteria have fully been completed, and a few have not been competed at all. This leads to the judgment that in $14 \%$ of the cases the performance of social work has been partially qualitative. It is crucial to have an in-depth analysis to determine the reasons for partial or non-completion of certain criteria.

4. Only 6 cases exhibit lack of completion of several criteria, partial completion of many criteria and no criteria fully completed. The score varies between 16 and 22 points there. The authors of the research indicate that $6 \%$ of case work are of poor quality, thus also leads to no results. In order to avoid low performance doing case work, regular quality assessment is of a high importance, which includes assessment of separate intervention phases and holistic evaluation of it using case work assessment instrument designed by the authors. According to the authors' opinions, regular quality assessment will allow for early diagnosis of shortcomings of the process of carrying out case work and will prevent of such cases to arise. Thus, a better understanding of the social situation of the client may be ensured, client's participation in solving the problems may be fostered much more effectively, which eventually leads to targeted and well planned attainment of successful outcome of the case.

5. By analysing various cases, it has been noted that the supervisors have to address that phase of case work when the aims of the works are being defined and tasks set. The assessment results of the research show that in $71 \%$ of the cases where the initially defined aims and tasks were specific 


\section{Int. Conf. SOCIETY. HEALTH. WELFARE.}

and exact, full completion of the defined targets and the results that comply with the expected outcome of case work was observed. This finding alone proves the importance of clarity in target and task design as an influential factor on the quality of case work.

6. In $19 \%$ of the cases, the aims and tasks were rather general. However, in $25 \%$ of the cases the aim was partially obtained, thus partially complying with the expected outcomes. Nevertheless, in $10 \%$ of the cases under the scope of analysis, the authors were unable to discover whether any aims and tasks were put down in written form, thus it was impossible to evaluate the content of them.

7. In $4 \%$ of the cases the aim of intervention was not reached or the result obtained was different from the expected outcome. In $3 \%$ of these cases the aim was not reached at all, as they had been defined too vaguely and over-generally. All of the data gathered allows for the conclusion that a substantial part of social workers lack the necessary knowledge, which indicates the importance of additional training on how to define and set aims when doing case work.

\section{Discussion}

The research is the first attempt to do the evaluation of case work in Latvia. It also must be acknowledged that it is not common in Latvia to use standardised assessment tools; thus, the evaluation questionnaire (13 criteria) designed by the authors of this study may serve as a contribution into the development of case work evaluation system in Latvia.

The authors are aware that the newly designed assessment instrument is the basis for both the discussion on how to do case wok assessment and for further analysis of quality of case work.

The empirical study indicated that in $80 \%$ of the cases social assistance has been provided in its highest quality, in $14 \%$ - of a rather reasonable quality, but in $6 \%$ of the cases it was evaluated as being of poor quality. The question is what constitutes to those $20 \%$ of low performance of social work. It may be assumed that the poor quality may be caused by overload of social workers. If a social worker has been exposed to excessive work load, they are insufficient in meeting their responsibilities, for example, the necessary information has not been obtained completely, assessment of social functioning and/or cooperation has not been performed, no social risks have been evaluated etc., which affect efficient attainment of the results. Riga Welfare Department's data reveal that a social worker works on average with 49 cases, but apart from the management and supervision of these cases they have much more responsibilities (for example, reaching agreement on social benefactors' inclusion in doing social work, issuing references on performed visitations of the clients, mentoring of university students, processing of information on clients who have resisted to take part in paid temporary public work). This shows the need for further discussions and researches on the amount of work load of social workers when doing case work, and on how various factors, including the number of cases per social worker, influence the quality of social assistance provision. The analysis of work load should be performed, and the optimum number of client cases or standards should be defined. Nevertheless, social worker supervisors have to address the ability of social workers to formulate client centred aims and design attainable tasks.

\section{Conclusions}

Social service system has developed rapidly over the last 20 years in Latvia. Social Offices have been established in all municipalities, various social services are introduced, among which case work takes a significant place. Currently the evaluation of social service provision has become crucial in Latvia. Thus, the research is considered as the attempt to evaluate case work and analyse the obtained data.

The data of the research allows for conclusion that case work and successful achievement of the set targets are affected not only by quantitative factors like overload of social workers, understaffing and rotation of them, but also the qualitative means by which the targets have been set and action 


\section{SHS Web of Conferences}

plan designed during the initial stages of case work. Thus, in order to define the quality of completion of intervention tasks, it is important to do systematic overall evaluation of case work, as well as the assessment of every phase of work has to be performed and analysis of the obtained results carried out. Evaluation of case work, by using the tool of assessment designed by the authors of this study, will lead to a timely discovery of shortcomings of the process and will prevent the rise of those, which, however, will ensure effective participation of the client in solving the problem and will lead towards attainment of the desired outcome.

Suggestions for further studies in the field, as indicated by the authors include:

1. Research into the work load of social workers in performing case work, and how various factors, among which is the number of cases per social worker, affect social assistance provision. The analysis of work load should be performed, and the optimum number of client cases or standards should be defined.

2. A comparative study must be carried out on case work quality from the perspectives of social workers and clients.

\section{References}

[1] Ambrosino, R., Heffernan, J., Shuttlesworth, G., Social Work and Social Welfare: An Introduction/3rd ed. - St.Paul: West Publishing Company.1997. - pp.106-107.

[2] Engel R., Schut R., The Practice of Research in Social Work - Thousand Oaks, London, New Delhi: Sage Publications. 2005. - p.13

[3] Rīgas domes Labklājības departamenta Gadagrāmata "Sociālā sistēma un veselības aprūpe Rīgā 2011. gadā", Rīga, 2012. (http://www.ld.riga.lv/labklajibas-departamenta-gadagramatas.html skatīts 14.10.2013.).

[4] Riga Welfare Department 27.04.2011. Regulations No. DL-11-16-nts “About the Required Documentation of Client Cases of Riga Welfare Department", which define the volume of the required documentation and activities that have to be undertaken with case work (unpublished document)

[5] Regulations of the Cabinet of Ministers No. 291 (January 3, 2003), "Regulations for social work providers" // "Latvijas Vēstnesis", No.85 (2850), 06.06.2003. 